\title{
A novel design silicone oil removal cannula
}

\author{
Fevzi Akkan ${ }^{1}$, Dincer Dinc ${ }^{2}$ \\ ${ }^{1,2}$ Consultant Ophthalmologist, Department of Vitreoretinal Surgery, Dunyagoz Eye Hospital, Istanbul, Turkey
}

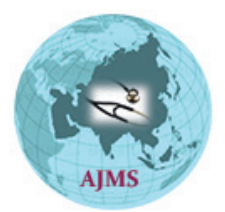

Background: Silicone oil, which is one of the most commonly used endotamponades in vitreoretinal surgery, is removed after a certain period of time in most cases. In this study, we present our results with a unique cannula that provides effective and safe silicone oil removal. Aims and Objectives: To assess the aids and success of silicone oil removal with a novel 23-gauge cannula for the patients who underwent pars plana vitrectomy and silicone oil injection before. Materials and Methods: 72 eyes of 64 patients who operated by the same surgeon (FA) between May 2017 and May 2019 were involved in the study. The primary indications were proliferative diabetic retinopathy in $46(63.9 \%)$ eyes and retinal detachment in $26(36.1 \%)$ eyes. Phacoemulsification and intraocular lens implantation (23 eyes), membrane peeling (23 eyes), internal limiting membrane peeling (5 eyes), and argon laser endo-photocoagulation (37 eyes) performed in the same session. Furthermore, perfluorocarbon remnants aspirated in 9 eyes and 17 eyes needed suturing. Descriptive statistical analyses achieved by SPSS 10.5 statistical software. Results: The mean follow-up time was $11.7+2.5$ months (between 3 and 23 months), and the mean age was $61.4+8.52$ years (between 44 and 69 years). 1000 centistokes (cSt) silicone oil was removed from $61(84.7 \%)$ eyes, and $5000 \mathrm{cSt}$ silicone oil was removed from $11(15.3 \%)$ eyes. The mean removal time was $2.04+0.1 \mathrm{~min}$ for $1000 \mathrm{cSt}$ silicone oil and $5.11+0.3$ min for $5000 \mathrm{cSt}$ silicone oil. 4 re-detachment and 3 vitreous hemorrhage observed in follow-up period. Post-operative silicone oil remnants were not detected in any patient. Conclusion: The unique 23-gauge cannula provides silicone oil removal without any conjunctival cut-down and sclerotomy enlargement. Thus, it reduces the duration of surgery and post-operative recovery period.

Key words: 23-G pars plana vitrectomy; A novel cannula; Silicone oil removal
Access this article online

Website:

http://nepjol.info/index.php/AJMS

DOI: 10.3126/ajms.v12i12.39998

E-ISSN: 2091-0576

P-ISSN: 2467-9100

Copyright (c) 2021 Asian Journal of Medical Sciences

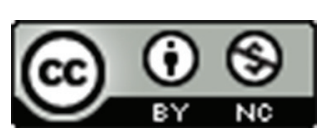

This work is licensed under a Creative Commons Attribution-NonCommercial 4.0 International License.

\section{INTRODUCTION}

Silicone oil began to be used in vitreoretinal surgery in 1962. Over time, it has become commonly used intraocular tamponade. ${ }^{1}$ Using silicone oil, quick visual rehabilitation is achieved. However, it can cause severe complications such as cataract, glaucoma, or keratopathy in aphakic eyes specially. The severity of complications are proportional to the duration of its stay in the eye. ${ }^{2,3}$

As a general opinion, to minimize the long-term complications of silicone oil; it is recommended to remove tamponade after achieving its purpose and stable retinal condition. ${ }^{4}$ Both anterior and posterior segment approaches can be performed for silicone oil removal.

\section{Aims and objectives}

To described a new cannula and approach for silicone oil removal through a $23-\mathrm{G}$ sclerotomy that provides additional endolaser photocoagulation and epiretinal membrane peeling without incision enlargement.

\section{MATERIALS AND METHODS}

72 eyes of the 64 patients who underwent active silicone oil removal in Dunyagoz Eye Hospital (Istanbul/Turkey) between May 2017 and May 2019 were included in the study. Pars plana vitrectomy and 1000 or 5000 centistokes (cSt) silicone oil injections were performed for proliferative diabetic retinopathy in $46(63.9 \%)$ eyes and retinal detachment in $26(36.1 \%)$ eyes, respectively. Moreover, $23(31.9 \%)$ eyes had cataract formation.

\footnotetext{
Address for Correspondence:

Dr. Dincer Dinc, Consultant Ophthalmologist, Kartaltepe Mh. Dost Sk. Yetkinagac 1 Apt. No: 8/5 Bakirkoy, Istanbul, Turkey

Mobile: +905059179556. E-mail: drdincerdinc@hotmail.com
} 
None of the silicone oil-related complications such as glaucoma or keratopathy were observed. The reason for silicone oil removal in clinically stable retinas was to avoid silicone oil associated long-term complications. None of the eyes were hypotonic. The best-corrected visual acuity (BCVA) was measured on the Snellen chart and converted to a logarithm of the minimal angle resolution (LogMAR) equivalents for statistical analyses. Goldmann applanation tonometer was used for intraocular pressure (IOP) measurement. Slit-lamp examination findings of the cornea, conjunctiva, and anterior segment structures were noted. For funduscopic examination binocular indirect ophthalmoscope and contact widefield lenses were used. Before the silicone oil removal, all retinas were attached and stable.

The design of the study was approved by Institutional Review Board. All patients signed an informed consent before the surgery. and all data collected in agreement with Declaration of Helsinki.

Post-operative IOP changes were studied with SPSS 10.5 for windows statistical software, and $\mathrm{P}<0.05$ was considered statistically significant for all of the analyses.

\section{Description of the special cannula}

A silicone cap and ring around the brass tip of the special 19-gauge silicone oil removal cannula helps it to seal to the funnel shaped 23-gauge valveless trocar. Together with the connected tubing system, this special cannula can be assembled to viscous fluid extraction section of the vitrectomy machine (Figure 1). Once the cannula is inserted to the aperture of the valveless trocar, by the high vacuum it is sucked into the trocar obtaining a tight seal. Therefore, silicone oil can be extracted safely, quickly, and without interruption (Figures 2 and 3).

\section{Surgical technique}

The surgeries were performed under posterior subtenon injection of $5 \mathrm{mg}$ bupivacaine HCL and $60 \mathrm{mg}$ lidocaine HCL.

Leica surgical microscope and BIOM non-contact system were used for visualization. Silicone oil removed through 23-G sclerotomies with the special cannula and D.O.R.C Associate ${ }^{\circledR}$ Dual System.

Pupilla was dilated with tropicamide $1 \%$ and cyclopentolate $1 \%$ before surgery. $5 \%$ povidone-iodine drops were used for sterilization.

After the first inferotemporal sclerotomy was created, a $23-G$ infusion cannula was inserted into the trocar.
The infusion bottle height set to $65 \mathrm{~cm}$ before placing superotemporal and superonasal $23-\mathrm{G}$ trocars. One of the trocars which were combined with the cannula was valveless. To prevent post-operative leakage, all trocars were inserted to the pars plana through $45^{\circ}$ scleral tunnels after

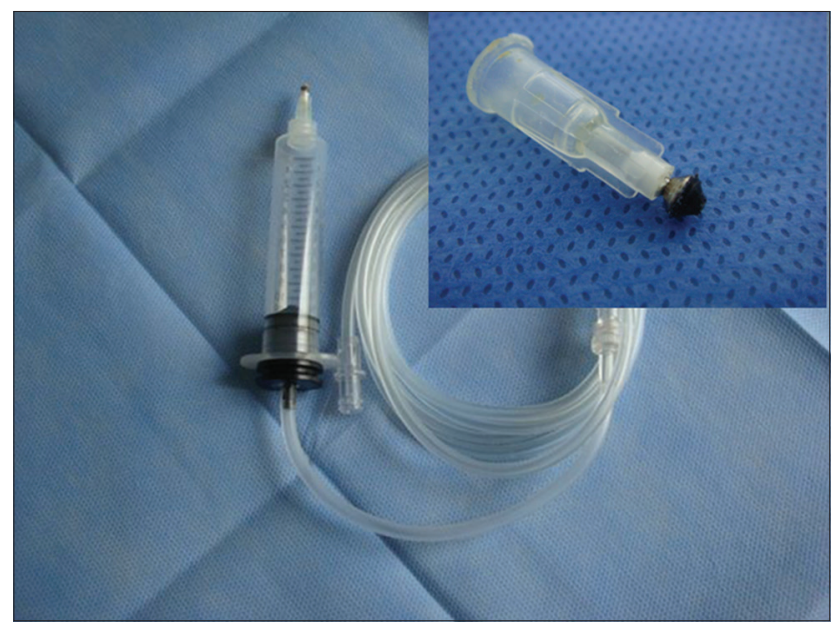

Figure 1: Hand-piece and cannula tip

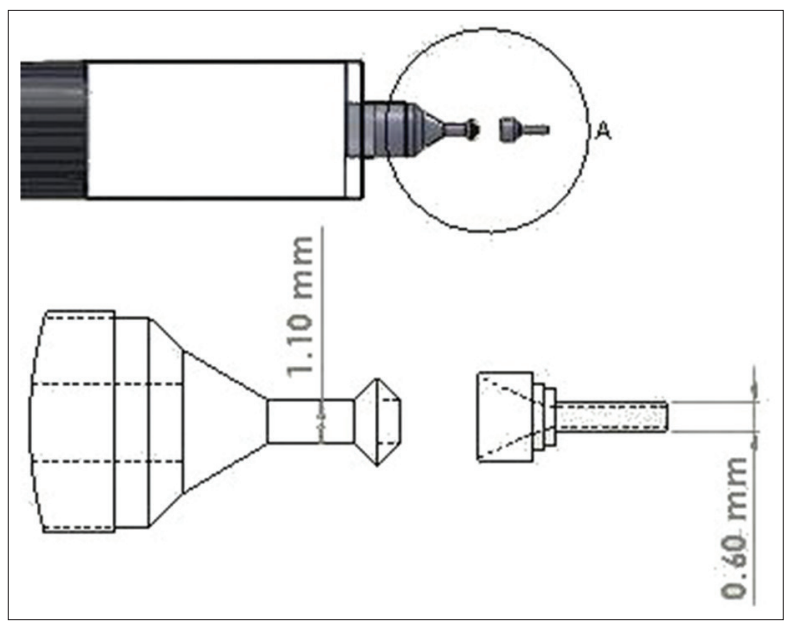

Figure 2: Drawing of the cannula tip and trocar

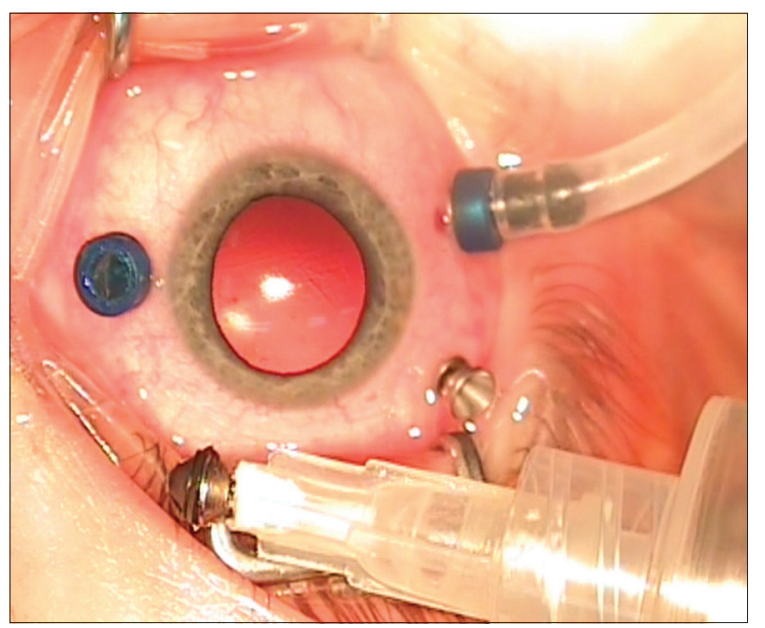

Figure 3: Appearance of the silicone cannula tip intraoperatively 
sclerotomies had created using microvitreoretinal knives. The bottle height increased to $90 \mathrm{~cm}$. 1000 or $5000 \mathrm{cSt}$ silicone oils started to be aspirated using a 500-600 mmHg vacuum with the new design cannula which has a special 19-G silicone cap and ring around the brass tip that is compatible with the valveless trocar. As the silicone oil bubble gets smaller and smaller, the cannula was just removed to let the passive passage of the last tiny bubble (Figure 4).

Subsequently, to remove all silicone oil remnants; the airfluid exchange was performed in all eyes after putting the valve of the trocar. After retinal examination with a $23-G$ light probe, endolaser photocoagulation was performed in 37 eyes and perfluorocarbon remnants aspirated was performed in 9 eyes. In addition to silicone oil removal, membrane peeling in 23 eyes and ILM peeling in 5 eyes was also performed in the same session.

Phacoemulsification and intraocular lens (IOL) implantation was performed in 23 eyes. Initially, 23-G trocars were inserted as explained above. Phacoemulsification surgery was performed by "phaco chop" or "stop and chop" technique later. The anterior chamber was filled with an ophthalmic viscosurgical device. After silicone oil removal, foldable acrylic posterior chamber IOL was implanted into the capsular bag so that posterior capsule integrity was preserved in all combined phacoemulsification and silicone oil removal cases.

The height of bottle was decreased to $60 \mathrm{~cm}$ at the end of the surgical procedure. The infusion line was temporarily shut down before each trocar was removed. Adequate pressure with a cotton swab was applied to the sclerotomies and the infusion line was activated after each trocar had been removed. Finally, the infusion cannula was removed. The sclerotomies were evaluated for fluid/

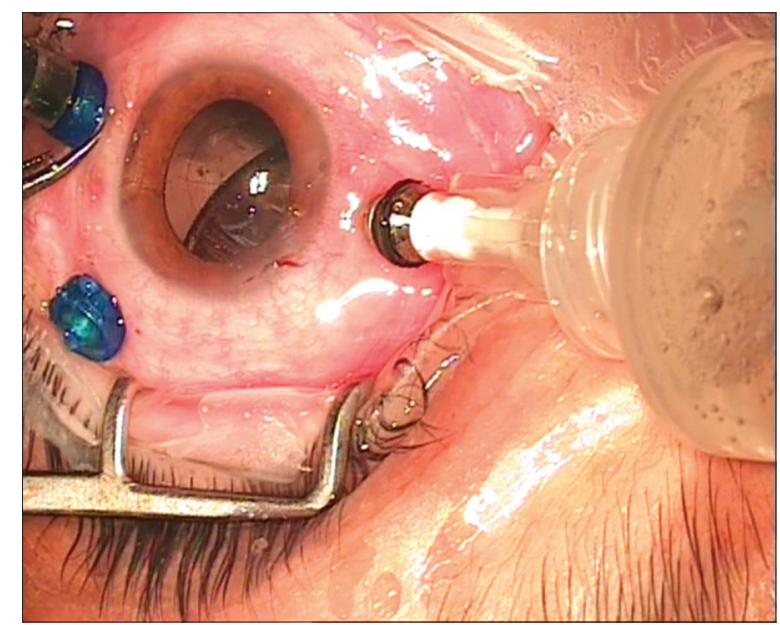

Figure 4: Combined phaco and silicone oil removal with the special cannula gas exchange related bleb formation and wound leakage. The conjunctival massage was performed on sclerotomies to avoid post-operative hypotony. Suture placement was needed in 17 eyes.

The operation was terminated after subconjunctival steroid and antibiotic injection.

The patients were examined on post-operative $1^{\text {st }}$ day, $1^{\text {st }}$ week, $1^{\text {st }}$ month, $6^{\text {th }}$ months, and $1^{\text {st }}$ year. Silicone oil removal times were recorded during surgeries.

\section{RESULTS}

The mean age of $37(57.8 \%)$ male and 27 (42.2\%) female patients was $61.4+8.52(44-69)$ years. Average time between silicone oil injection and intake was $9.36+$ 5.14 months. Mean post-operative follow-up time was $11.7+2.5(3-23)$ months. There were 1000 cSt silicone oil in 61 eyes and $5000 \mathrm{cSt}$ silicone oil in 11 eyes. Average silicone oil removal times were $2.04+0.1$ minutes for 1000 cSt silicone oil and $5.11+0.3 \mathrm{~min}$ for $5000 \mathrm{cSt}$ silicone oil (Table 1).

Mean pre-operative IOP was $15.47+3.01 \mathrm{mmHg}$, and mean post-operative IOPs on $1^{\text {st }}$ day, $1^{\text {st }}$ week, and $1^{\text {st }}$-month visits were $14.15+3.91,15.43+2.52$, and $16.12+0.85$, respectively. There was no significant statistical difference between pre- and post-operative IOP levels ( $\mathrm{P}>0.05)$. Choroidal detachment, endophthalmitis, and post-operative cataract development were not observed in any patient. There was no clinically significant macular edema or corneal decompensation in any case. 4 re-detachment and 3 vitreous hemorrhages were detected in the follow-up period. Silicone oil remnants were not observed in any patient. None of the patient had decrease in visual acuity. BCVA improved in $42(58.3 \%)$ eyes and not changed in $30(41.7 \%)$ eyes. Mean pre-operative BCVA was $1.6+0.2$ LogMAR, and the mean post-operative BCVA was $1.3+$ $0.2 \log M A R$ at the last visit.

\section{DISCUSSION}

Many techniques have been described for intraocular silicone oil removal. ${ }^{3,5,6}$ Silicone oil can be removed by active suction or can be flowed out passively ${ }^{3}$ through a sclerotomy port ${ }^{6}$ by filling vitreous cavity with balanced salt

\begin{tabular}{lcc}
\multicolumn{4}{l}{ Table 1: Silicone oil removal times } \\
\hline Type of silicone oil & $\mathbf{1 0 0 0} \mathbf{~ S t}$ & $\mathbf{5 0 0 0} \mathbf{~ S t}$ \\
\hline Number of patients & $61(84.7 \%)$ & $11(15.3 \%)$ \\
Removal time & $2.04+0.1 \mathrm{~min}$ & $5.11+0.3 \mathrm{~min}$ \\
\hline cSt: Centistokes & &
\end{tabular}


solution. Silicone removal with anterior segment approach has severe limitations in case of additional vitreoretinal procedure required.

If compared with the 19-G or 20-G surgery techniques, one of the most important advantages of the $23-G$ vitreoretinal surgery system is allowing less sutureless surgery. Sutureless surgery eliminates the localized inflammation and irritation that suture materials can cause. Therefore, it provides postoperative inflammation lower and patient rehabilitation faster. $^{7-9}$ We performed silicone oil removal in aphakic, pseudophakic, and phakic eyes under posterior subtenon's anesthesia. During the surgeries, suture placement was needed in $17(23.6 \%)$ eyes.

Qin et al., ${ }^{10}$ reported 29 min average surgery time to remove 5000 cSt silicone oil by moving back a $10-\mathrm{mL}$ syringe connected to a $20-G$ Vasocan cannula through corneal incision in aphakic eyes. Another study reported that active silicone oil removal takes $4-5 \mathrm{~min} .{ }^{6}$ Yildirim et al., ${ }^{11}$ reported 9 min average surgical time for passive removal of 1300 cSt silicone oil and 7.6 min average surgical time for active aspiration of $5700 \mathrm{cSt}$ silicone oil. Kapran and Acar $^{12}$ reported $3.31+1.14 \mathrm{~min}$ and $10.27+0.48 \mathrm{~min}$ mean removal time for $1000 \mathrm{cSt}$ and $5000 \mathrm{cSt}$ silicone oil, respectively, with their new $25-\mathrm{G}$ active drainage technique. Kapran and Acar ${ }^{13}$ attempted to remove 5000 cSt silicone oil through 25-G transconjunctival sclerotomies passively. However, they did not use their own techniques to remove the $5000 \mathrm{cSt}$ silicone oil, as the passive removal of the oil takes a very long time.

Oh et al., ${ }^{14}$ reported average silicone oil removal time 1.49 $\pm 0.43 \mathrm{~min}$ for $1000 \mathrm{cSt}$ silicone oil and $7.12 \pm 1.27 \mathrm{~min}$ for $5700 \mathrm{cSt}$ silicone oil, respectively, with a 23 gauge transconjunctival cannula using an external vacuum pump.

In our study, active removal of $1000 \mathrm{cSt}$ silicone oil through $23-G$ trocars was achieved in a mean period of $2.04+0.1 \mathrm{~min}$ and $5.11+0.3 \mathrm{~min}$ in $5000 \mathrm{cSt}$ silicone oil which is rather short. In addition, there was not any statistically significant difference between pre- and post-operative IOP levels $(\mathrm{P}>0.05)$. Similar to our findings, previous studies with $25-\mathrm{G}$ and $23-G$ systems also reported that differences between IOP in the $1^{\text {st }}$ postoperative day were statistically insignificant. ${ }^{7,15,16}$

In this study, we did not experience any endophthalmitis. We share the same opinion with Lakhanpal et al., ${ }^{15}$ who stated that proper preparation with povidone-iodine is essential to reduce the risk of contamination of the vitreous with conjunctival flora throughout trocar insertion.

Reported re-detachment rate after silicone oil removal varied between $6 \%$ and $33 \% .^{3,17-19}$ We reported $4(5.5 \%)$ re-detachment cases in our study which is slightly lower than literature knowledge.

In our study, visual acuities either improved or remained unchanged in all patients. BCVA improved in 42 (58.3\%) eyes and remained unchanged in $30(41.7 \%)$ eyes. Mean pre-operative BCVA was 1.6 for LogMAR and mean post-operative BCVA at last visit was 1.3 for LogMAR.

\section{Limitations of the study}

In our study, the efficacy and safety of a unique silicone oil removal cannula was investigated and the results were compared with the literature knowledge. Different silicone oil extraction techniques could be performed for the different patient groups and a comparison could be made with the cannula we presented in the study.

\section{CONCLUSION}

Consequently, this novel design special cannula provides a simple, safe, and quick approach for active removal of 1000 cSt or 5000 cSt silicone oil through a 23-G valveless trocar. In addition, since it allows the operation to be performed through a small scleral incision, it increases the postoperative patient comfort and shortens the recovery time.

\section{ACKNOWLEDGMENT}

We would like to thank all the hospital staff who contributed to our study.

\section{REFERENCES}

1. Cibis PA, Becker B, Okun E and Canaan S. The use of liquid silicone in retinal detachment surgery. Arch Ophthalmol. 1962;68:590-599.

https://doi.org/10.1001/archopht.1962.00960030594005

2. Abrams GW, Azen SP, Barr CC, Lai MY, Hutton WL, Trese MT, et al. The incidence of corneal abnormalities in the Silicone study. Silicone study report 7. Arch Ophthalmol. 1995;113(6):764-769. https://doi.org/10.1001/archopht.1995.01100060090039

3. Casswell AG and Gregor ZJ. Silicone oil removal. II. Operative and postoperative complications. $\mathrm{Br} \mathrm{J}$ Ophthalmol. 1987;71(12):898-902.

https://doi.org/10.1136/bjo.71.12.898

4. Gallemore RP and McCuen BW. Silicone oil in vitreoretinal surgery. In: Ryan SJ and Wilkinson CP, editors. Retina. $4^{\text {th }}$ ed. Philadelphia, PA: Elsevier, Mosby; 2006. p. 2231. https://doi.org/10.1016/b978-0-323-02598-0.50136-1

5. Gonvers M. Temporary silicone oil tamponade in the management of retinal detachment with proliferative vitreoretinopathy. Am J Ophthalmol. 1985;100(2):239-245. https://doi.org/10.1016/0002-9394(85)90788-3

6. Garodia VK and Kulkarni A. Silicone oil removal using vitrectomy 
machine: A simple and safe technique. Retina. 2001;21(6):685-687. https://doi.org/10.1097/00006982-200112000-00027

7. Fujii GY, De Juan E Jr., Humayun MS, Chang TS, Pieramici DJ, Barnes A, et al. Initial experience using the transconjunctival sutureless vitrectomy system for vitreoretinal surgery. Ophthalmology. 2002;109(10):1814-1820. https://doi.org/10.1016/s0161-6420(02)01119-3

8. Chalam KV and Shah VA. Successful management of cataract surgery associated vitreous loss with sutureless small-gauge pars plana vitrectomy. Am J Ophthalmol. 2004;138(1):79-84. https://doi.org/10.1016/j.ajo.2004.02.018

9. Chang CJ, Chang YH, Chiang SY and Lin LT. Comparison of clear corneal phacoemulsification combined with 25-gauge transconjunctival sutureless vitrectomy and standard 20-gauge vitrectomy for patients with cataract and vitreoretinal diseases. J Cataract Refract Surg. 2005;31(6):1198-1207. https://doi.org/10.1016/j.jcrs.2004.11.041

10. Qin B, Zhao $T$ and Huang L. Removal of silicone oil from aphakia: Use of a self-sealing corneal incision. Am J Ophthalmol. 2004;138(6):1055-1057.

https://doi.org/10.1016/j.ajo.2004.06.037

11. Yildirim R, Aras C, Ozdamar A and Bahcecioglu A. Silicone oil removal using a self-sealing corneal incision under topical anesthesia. Ophthalmic Surg Lasers. 1999;30(1):24-26. https://doi.org/10.3928/1542-8877-19990101-06

12. Kapran $Z$ and Acar N. Active removal of silicone oil with 25-gauge sutureless system. Retina. 2007;27(8):1133-1135. https://doi.org/10.1097/iae.0b013e3181237cde
13. Kapran Z and Acar N. Removal of silicone oil with 25-gauge transconjunctival sutureless vitrectomy system. Retina. 2007;27(8):1059-1064.

https://doi.org/10.1097/iae.0b013e3180592c13

14. Oh HJ, Chang W and Sagong M. Efficacy and safety of active silicone oil removal through a 23-gauge transconjunctival cannula using an external vacuum pump. Int $\mathrm{J}$ Ophthalmol. 2015;8(2):347-352.

15. Lakhanpal RR, Humayun MS, De Juan E Jr., Lim JI, Chong LP, Chang TS, et al. Outcomes of 140 consecutive cases of 25-gauge transconjunctival surgery for posterior segment disease. Ophthalmology. 2005;112(5):817-824. https://doi.org/10.1016/j.ophtha.2004.11.053

16. Eckardt C. Transconjunctival sutureless 23-gauge vitrectomy. Retina. 2005;25(2):208-211. https://doi.org/10.1097/00006982-200502000-00015

17. Franks WA and Leaver PK. Removal of silicone oil: Rewards and penalties. Eye. 1991;5(5):333-337. https://doi.org/10.1038/eye.1991.53

18. Lesnoni G, Rossi T, Nistri A and Boccassini B. Long-term prognosis after removal of silicone oil. Eur $\mathrm{J}$ Ophthalmol. 2000;10(1):60-65. https://doi.org/10.1177/112067210001000110

19. Scholda C, Egger S, Lakits A and Haddad R. Silicone oil removal: Results, risks and complications. Acta Ophthalmol Scand. 1997;75(6):695-699. https://doi.org/10.1111/j.1600-0420.1997.tb00633.x

\section{Authors Contribution:}

FA- Concept and design of the study, prepared first draft of manuscript and revision of the manuscript; DD- Interpreted the results; reviewed the literature and manuscript preparation, statistical analysis and revision of the manuscript.

\section{Work attributed to:}

Dunyagoz Eye Hospital, Department of Vitreoretinal Surgery, Etiler, Besiktas, Istanbul - 34337, Turkey

\section{Orcid ID:}

Dr. Fevzi Akkan - (D) https://orcid.org/0000-0001-9066-6225

Dr. Dinc Dincer - (D https://orcid.org/0000-0001-5906-7208

Source of Funding: None, Conflicts of Interest: None. 